\title{
Effect of virtual reality in Parkinson's disease: a prospective observational study
}

\author{
Efeito da realidade virtual na doença de Parkinson: estudo observacional prospectivo \\ Maria Izabel Rodrigues Severiano', Bianca Simone Zeigelboim², Hélio Afonso Ghizoni Teive², Geslaine \\ Janaina Barbosa Santos ${ }^{4}$, Vinícius Ribas Fonseca²
}

\begin{abstract}
Objective: To assess the effectiveness of balance exercises by means of virtual reality games in Parkinson's disease. Methods: Sixteen patients were submitted to anamnesis, otorhinolaryngological and vestibular examinations, as well as the Dizziness Handicap Inventory, Berg Balance Scale, SF-36 questionnaire, and the SRT, applied before and after rehabilitation with virtual reality games. Results: Final scoring for the Dizziness Handicap Inventory and Berg Balance Scale was better after rehabilitation. The SRT showed a significant result after rehabilitation. The SF-36 showed a significant change in the functional capacity for the Tightrope Walk and Ski Slalom virtual reality games ( $p<0.05)$, as well as in the mental health aspect of the Ski Slalom game $(p<0.05)$. The Dizziness Handicap Inventory and Berg Balance Scale showed significant changes in the Ski Slalom game $(p<0.05)$. There was evidence of clinical improvement in patients in the final assessment after virtual rehabilitation. Conclusion: The Tightrope Walk and Ski Slalom virtual games were shown to be the most effective for this population.
\end{abstract}

Keywords: Parkinson's disease; postural balance; quality of life; vestibular nuclei.

\section{RESUMO}

Objetivo: Verificar a eficácia dos exercícios de equilíbrio com realidade virtual (RVi) na doença de Parkinson. Métodos: Dezesseis pacientes foram submetidos a uma anamnese, exames otorrinolaringológico e vestibular, ao Dizziness Handicap Inventory (DHI), Escala de Equilíbrio de Berg (EEB), questionário SF-36 e o Teste de Sentar e Levantar (TSL) que foram aplicados antes e após a reabilitação com RVi. Resultados: Os resultados dos escores finais do DHI e EEB foram melhores após a reabilitação. O TSL apresentou resultado significativo após a reabilitação. O SF-36 demonstrou alteração significativa da capacidade funcional para os jogos Tightrope Walk e Ski Slalom ( $p<$ $0,05)$ e da saúde mental para o jogo Ski Slalom ( $p<0,05)$. O DHI e EEB apresentaram alterações significativas no jogo Ski Slalom ( $p<0,05)$. Houve melhora clínica evidente dos pacientes após reabilitação virtual. Conclusão: Os jogos virtuais Tightrope Walk e o Ski Slalom foram os mais eficazes.

Palavras-chave: doença de Parkinson; equilíbrio postural; qualidade de vida; núcleos vestibulares.

The prevalence of degenerative diseases, such as Parkinson's disease (PD) and Alzheimer's disease, has become more and more significant ${ }^{1}$ with the increase in life expectancy observed worldwide. Parkinson's disease is a neurodegenerative disease typically diagnosed from a combination of motor symptoms that include bradykinesia, stiffness, tremor and postural instability ${ }^{2}$. The characteristic functional disorder is a dopaminergic deficit secondary to the degeneration of the substantia nigra pars compacta. The specific cause of this degeneration is obscure and is probably multifactorial, including genetic predisposition, oxidative stress, and environmental factors, among others ${ }^{3}$.

The age group usually affected is between 50 and 70 years old, peaking in the 60s. The incidence in males is slightly higher than in females. Patients younger than 40 years old, and even 21-year-olds, may suffer from this disease. The latter case refers to juvenile $\mathrm{PD}$ and the former one to early onset $\mathrm{PD}^{4}$.

In the mostly-affected older PD population, there is an impairment in the ability of the central nervous system (CNS) to process vestibular signals (visual and proprioceptive)

${ }^{1}$ Instituto Federal de Educação, Ciência e Tecnologia do Paraná, Curitiba PR, Brasil;

2 Universidade Tuiuti do Paraná, Departamento de Otoneurologia, Curitiba PR, Brasil;

${ }^{3}$ Universidade Federal do Paraná, Hospital de Clínicas, Serviço de Neurologia, Curitiba PR, Brasil;

4Instituto Federal de Educação, Ciência e Tecnologia do Paraná, Departamento de Fisioterapia, Curitiba PR, Brasil;

Correspondence: Bianca Simone Zeigelboim; Departamento de Otoneurologia da Universidade Tuiuti do Paraná; Rua Sydnei Antonio Rangel Santos, 238;

82515-180 Curitiba PR, Brasil; E-mail: biancacwb@yahoo.com.br

Conflict of interest: There is no conflict of interest to declare.

Received 02 August 2017; Received in final form 16 November 2017; Accepted 18 November 2017. 
responsible for balance, with a decrease in the capacity to change postural adaptive reflexes. Symptoms such as vertigo and/or dizziness and balance problems are implicated in these disorders ${ }^{5}$.

Postural stability depends on the integrity of the vestibular system (labyrinth, vestibulocochlear nerve, nuclei, pathways and interconnections within the CNS), on the somatosensory system (sensory receptors located in the tendons, muscles and joints), and on vision. In PD, postural instability occurs as the disease advances, causing functional dependence, increasing the risk of falls and mortality among the elderly population ${ }^{5,6}$.

The object of vestibular rehabilitation is to modify the postural control system by means of specific and repetitive physical exercises in different conditions. These exercises have been identified as acting physiologically on the vestibular system, and are considered a therapeutic device for its activation, based on the central mechanisms of neuroplasticity, known as adaptation, habituation and substitution, to obtain vestibular compensation ${ }^{7,8}$. Vestibular rehabilitation, by means of virtual reality (VR) involves immersion into an imaginary world; environmental perception is altered by an artificial stimulus generating a sensory conflict, which changes the gain of the vestibulo-ocular reflex. The use of VR as an instrument of assessment and/or rehabilitation enables the therapist to go beyond the constraints of the traditional tools, strengthening the effects of the already-existing interventions and maximizing their efficiency. ${ }^{9}$ In Brazil, the use of virtual games in rehabilitation has been demonstrated in some studies. However, there has been little discussion on game selection, although that is essential for the recommendation of its therapeutic use.

The objective of the current study was to verify the effectiveness of balance exercises using VR in patients suffering from PD.

\section{METHODS}

\section{Participants and study design}

This study was approved by the Ethics Board - Brazil Platform, number 832.502/2014 Sociedade Evangélica Beneficente, Curitiba, Paraná, Brazil and authorized by the patients in the free informed consent form.

A prospective observational cohort study was carried out. The sample comprised 16 patients (six females and 10 males) with PD, from the Internal Medicine Department, Hospital das Clínicas, and from the Association of Patients with Parkinson's Disease in the city of Curitiba, Paraná State, Brazil. The PD diagnoses were confirmed according to the criteria of the Queen Square Brain Bank, applied by the Association. The patients' ages were between 18 and 82 years (mean age of 57.5 years and standard deviation of 18.7 years). The mean duration of the disease was 5.1 years, standard deviation of 3.2 (minimum time of one year and maximum time of 11 years).

The study inclusion criteria were adult patients with PD, absence of middle-ear diseases, no use of gait devices, and not previously given any rehabilitative therapies. Patients excluded from the study had otologic disorders, were unable to understand and respond to simple verbal commands, or had severe visual deficits or other impairments that would prevent them from performing the proposed procedures.

\section{Procedures}

All patients underwent an otorhinolaryngological assessment, anamnesis and vestibular system screening with digital vector electronystagmography (Neurograff Eletromedicina Ltda, São Paulo/SP, Brazil). Subsequently, the Dizziness Handicap Inventory (DHI) ${ }^{10}$, Berg Balance Scale (BBS) ${ }^{11}$, Medical Outcomes Study 36-Item Short-Form Health Survey $(\mathrm{SF}-36)^{12}$ and the Sitting-Rising Test (SRT) ${ }^{13}$ were applied. The DHI, BBS, SF-36, and the SRT were applied before rehabilitation ( $1^{\text {st }}$ assessment), and after the $20^{\text {th }}$ session of rehabilitation ( $2^{\text {nd }}$ assessment), with the aim of observing the postintervention changes.

\section{Dizziness handicap inventory}

The DHI (adapted for the Brazilian population) is a questionnaire comprising 25 questions, divided into physical (seven questions), emotional (nine questions), and functional (nine questions) domains. The physical domain of the DHI examines the relationship between dizziness experiences and eye, head and body movements. The emotional domain assesses the fear of going out or staying home alone, shame about the clinical symptoms, concerns with self-image, difficulty focusing, feelings of incapability, depression, and problems with family and social relationships. The functional domain detects impaired performance in professional, household, social, and leisure aspects. Each item has three possible responses: "affirmative" (4 points); "sometimes" (2 points), and "negative" (0 points). Hence, the maximum score for the DHI is 100 points.

\section{Berg balance scale}

The BBS assesses functional balance performance in 14 activities of daily life wherein the participant performs a series of timed body-balance control tasks. Each item has an ordinal five-choice response scale ranging from 0 to 4 points, where 0 indicates the lowest level of balance function, and 4 the highest. It scores low, medium and high fall risk (100\% fall risk).

\section{Medical outcomes study SF-36}

Intervention efficacy is often assessed by comparing preand post-intervention SF-36 results, as was done here. The SF-36 is a 36-item questionnaire that assesses quality of life. It comprises eight components: functional capacity, physical 
aspects, pain, general health status, vitality, social aspects, emotional aspects, and mental health. Total SF-36 scores range from 0 to 100 , with a higher score representing a better general health status.

\section{Sitting-rising test}

This assesses the ability and mobility of the lower limbs during sitting and rising actions.

\section{Vestibular rehabilitation}

Vestibular rehabilitation is a therapeutic method used in body-balance rehabilitation. Nintendo Wii equipment, Wii-Remote and a Wii Balance Board were used. This platform measures the applied strength, and records slight balance changes by means of pressure sensors. At first, patients got familiar with the game and were instructed in the movements required to perform the test.

Four balance games were carried out (Soccer Heading, Table Tilt, Tightrope Walk and Ski Slalom) with strategies involving saccadic eye movements, optokinetic stimuli, head movement, static and dynamic balance, motor coordination, eye-foot coordination, circular pelvic movements, knee flexion-extension, ankle-hip movements, back-to-front and sideto-side movements and weight transfer, aiming at balance disorders and postural instability.

All patients carried out 20 VR sessions, 50 minutes each, twice a week, and were submitted to the same assessment questionnaires before, and after the end of the rehabilitation sessions.

\section{Statistical analysis}

Data analyses were carried out by means of Spearman's correlation tests and paired Student's t tests performed in Statistica 13.1 software. The significance level was 0.05 [5\%] in all cases.

A

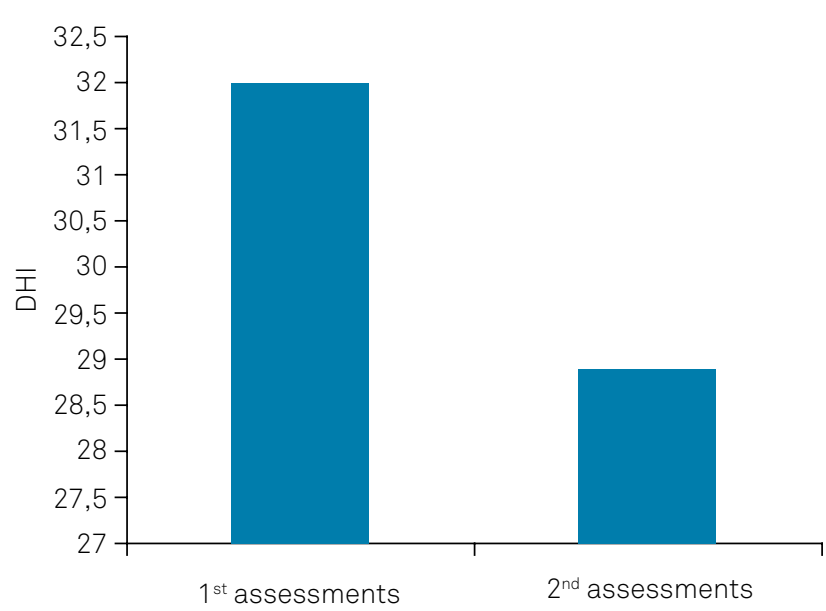

\section{RESULTS}

The most reported complaints in the anamnesis were: tremor and muscle stiffness (75\% each), imbalance (62.5\%), gait impairment and dizziness (43.7\% each), as shown in Table 1.

Vestibular screening was altered in five patients (31.2\%), with three patients $(18.7 \%)$ with peripheral vestibular deficit syndrome and two patients $(12.5 \%)$ with peripheral vestibular irritated syndrome. Screening was normal in 11 patients $(68.8 \%)$.

Final scores of the DHI and BBS questionnaires, comparing the $1^{\text {st }}$ assessment with the $2^{\text {nd }}$ assessment, are shown in Figure.

The SRT comparing the $1^{\text {st }}$ assessment with the $2^{\text {nd }}$ assessment, by applying the Student's t-test, showed a significant result ( $\mathrm{p}={ }^{*} 0.0222$ ), indicating an improvement in the ability and mobility of the lower limbs after training with VR.

Table 1. Symptoms in patients with Parkinson's disease $(n=16)$.

\begin{tabular}{lcc}
\hline Signs and symptoms & $\mathrm{n}$ & $\%$ \\
\hline Tremors & 12 & 75.0 \\
Muscle rigidity & 12 & 75.0 \\
Imbalance & 10 & 62.5 \\
Difficulty walking & 7 & 43.7 \\
Dizziness & 7 & 43.7 \\
Dysphagia & 6 & 37.5 \\
Paresthesia & 3 & 18.7 \\
\hline Tinnitus & 2 & 12.5 \\
Dysarthria & 2 & 12.5 \\
Headache & 1 & 6.2 \\
Tiredness when speaking & 1 & 6.2 \\
\hline
\end{tabular}

\section{B}

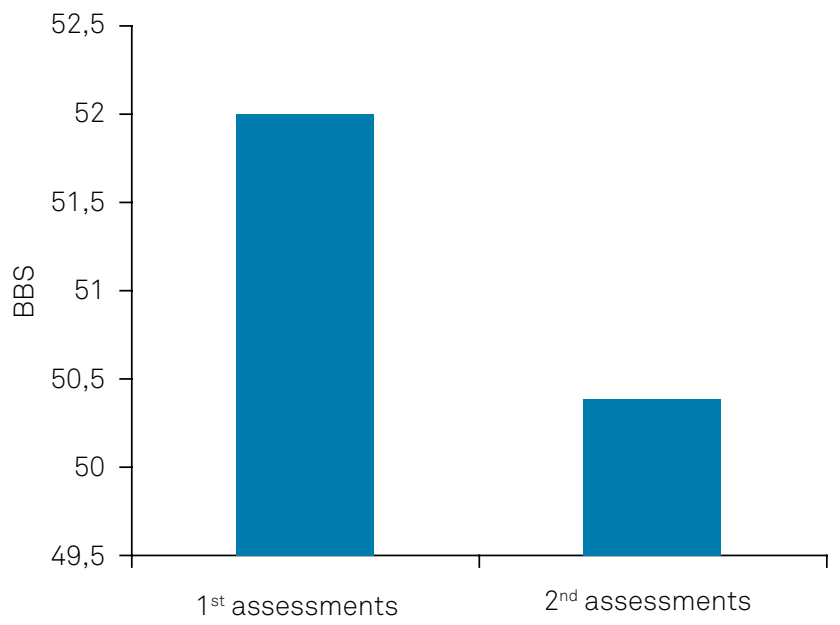


The result of the correlation between the balance games (Soccer Heading, Table Tilt, Tightrope Walk and Ski Slalom) and the DHI, BBS and SF-36 in the $1^{\text {st }}$ and $2^{\text {nd }}$ assessments, can be seen in Table 2.

The application of the Spearman's Correlation Test ( $1^{\text {st }}$ assessment) showed significant results for the Soccer Heading and Table Tilt games in the BBS ( $\left.p={ }^{*} 0.0059\right)$ and ( $p={ }^{*} 0.0396$ ) respectively, for the Tightrope Walk game in the BBS ( $\left.\mathrm{p}={ }^{*} 0.0093\right)$ and in the SF-36 - functional capacity $\left(\mathrm{p}={ }^{*} 0.0454\right)$; and for the Ski Slalom game in the DHI ( $\left.p={ }^{*} 0.0063\right)$, in the BBS ( $\left.p={ }^{*} 0.0124\right)$ and in the SF-36 - functional capacity $\left(\mathrm{p}={ }^{*} 0.0120\right)$.

The application of the Spearman's Correlation Test ( $2^{\text {nd }}$ assessment) showed a significant result for the Tightrope Walk game in the SF-36 - functional capacity ( $\left.p={ }^{*} 0.0045\right)$, and for the Ski Slalom game in the DHI $\left(p={ }^{*} 0.0061\right)$, in the BBS ( $\left.p={ }^{*} 0.0466\right)$, and in the SF-36 - functional capacity $\left(\mathrm{p}={ }^{*} 0.0069\right)$ as well as mental health $\left(\mathrm{p}={ }^{*} 0.0116\right)$. Comparing the results pre- ( $1^{\text {st }}$ assessment) and post-rehabilitation ( $2^{\text {nd }}$ assessment), there was significant improvement in the results of the applied questionnaires.

The comparative result between the virtual games $\left(1^{\text {st }}\right.$ and $2^{\text {nd }}$ assessments) can be seen in Table 3 .
The Student's T-test showed a significant difference for the Tightrope Walk $\left(\mathrm{p}={ }^{*} 0.0348\right)$ and Ski Slalom $\left(\mathrm{p}={ }^{*} 0.0053\right)$ games, indicating that these games were more effective for this population in relation to the other games used in the rehabilitative therapeutics. This improvement was reflected in the daily practice reported by the patients in the face of the discomfort caused by the disease.

\section{DISCUSSION}

In the analysis of the anamnesis, a higher occurrence of tremor, muscle stiffness and imbalance was observed. Tremor is the initial symptom of PD, featuring resting tremor that affects the hands, initially unilaterally, possibly asymmetric, in about $70 \%$ of the patients. Generally, the tremor is reduced or disappears with posture and movement, but increases with stress ${ }^{4}$, which was observed in the current study when patients reported particularly stressful or worrisome events that made the tremor more visible. In some patients, stiffness caused painful sensations, especially in the arms and shoulders. Parkinson's rigidity is plastic or extrapyramidal (muscle hypertonia observed in extrapyramidal disorders), unlike

Table 2.Clinical assessments and virtual reality game performance $(n=16)$.

\begin{tabular}{|c|c|c|c|c|c|c|c|c|}
\hline \multirow{2}{*}{ Assessment } & \multicolumn{2}{|c|}{ Soccer heading } & \multicolumn{2}{|c|}{ Table tilt } & \multicolumn{2}{|c|}{ Tightrope } & \multicolumn{2}{|c|}{ Ski Slalom } \\
\hline & $\mathrm{R}$ & $p$-value & $\mathrm{R}$ & $p$-value & $\mathrm{R}$ & $p$-value & $\mathrm{R}$ & $p$-value \\
\hline \multicolumn{9}{|c|}{$1^{\text {st }}$ assessment, pre-training } \\
\hline $\mathrm{DHI}$ & 0.3378 & 0.2007 & 0.4167 & 0.1083 & 0.4821 & 0.0586 & 0.6514 & 0.0063 \\
\hline BBS & 0.6553 & 0.0059 & 0.5186 & 0.0396 & 0.6274 & 0.0093 & 0.6083 & 0.0124 \\
\hline SF36 - FC & 0.0370 & 0.8918 & 0.3752 & 0.1522 & 0.5063 & 0.0454 & 0.6105 & 0.0120 \\
\hline SF36 - FA & 0.2147 & 0.4245 & 0.2639 & 0.3233 & 0.3815 & 0.1448 & 0.1689 & 0.5317 \\
\hline SF36 - PA & 0.2769 & 0.2991 & 0.1050 & 0.6987 & 0.2635 & 0.3241 & 0.3398 & 0.1979 \\
\hline SF36 - GHS & 0.0443 & 0.8706 & 0.0544 & 0.8413 & 0.1310 & 0.6288 & 0.1903 & 0.4803 \\
\hline SF36 - V & 0.1890 & 0.4833 & 0.0917 & 0.7355 & 0.1088 & 0.6884 & 0.2469 & 0.3567 \\
\hline SF36 - SA & 0.1487 & 0.5826 & 0.1684 & 0.5329 & 0.2377 & 0.3753 & 0.1441 & 0.5945 \\
\hline AF36 - EA & 0.2977 & 0.2628 & 0.0032 & 0.9907 & 0.3570 & 0.1747 & 0.2129 & 0.4285 \\
\hline AF36- MH & 0.2084 & 0.4385 & 0.1785 & 0.5084 & 0.0522 & 0.8479 & 0.3530 & 0.1798 \\
\hline \multicolumn{9}{|c|}{$2^{\text {nd }}$ assessment, post-training } \\
\hline $\mathrm{DHI}$ & 0.1538 & 0.5694 & 0.2877 & 0,2798 & 0.4825 & 0.0584 & 0.6534 & 0.0061 \\
\hline BBS & 0.4320 & 0.0947 & 0.2097 & 0,4356 & 0.3937 & 0.1313 & 0.5039 & 0.0466 \\
\hline SF36 - FC & 0.4000 & 0.1247 & 0.4446 & 0,0844 & 0.6707 & 0.0045 & 0.6455 & 0.0069 \\
\hline SF36 - FA & 0.0286 & 0.9163 & 0.1809 & 0,5027 & 0.0895 & 0.7418 & 0.3622 & 0.1680 \\
\hline SF36 - PA & 0.0718 & 0.7916 & 0.1330 & 0,6233 & 0.1011 & 0.7096 & 0.0329 & 0.9038 \\
\hline SF36 - GHS & 0.1304 & 0.6303 & 0.1235 & 0,6486 & 0.0052 & 0.9847 & 0.2828 & 0.2886 \\
\hline SF36 - V & 0.0520 & 0.8482 & 0.3779 & 0,149 & 0.1492 & 0.5814 & 0.2660 & 0.3194 \\
\hline SF36 - SA & 0.1882 & 0.4851 & 0.0688 & 0,8001 & 0.3741 & 0.1534 & 0.1590 & 0.5564 \\
\hline SF36 - EA & 0.3676 & 0.1613 & 0.2204 & 0,4121 & 0.0847 & 0.7552 & 0.2310 & 0.3893 \\
\hline SF36 - MH & 0.1481 & 0.5841 & 0.3802 & 0,1463 & 0.3107 & 0.2415 & 0.6129 & 0.0116 \\
\hline
\end{tabular}

R:Spearman's Correlation test; DHI:Dizziness Handicap Inventory; BBS: Berg Balance Scale; SF 36:Short Form; FC: functional capacity; FA: physical aspects; PA: pain; GHS: general health status; V: vitality; SA: social aspects; EA: emotional aspects; $\mathrm{MH}$ : mental health. Significant p-values are in bold. 
Table 3. Virtual reality game performance $(n=16)$.

\begin{tabular}{lcccccc}
\hline \multirow{2}{*}{ Game } & \multicolumn{2}{c}{$1^{\text {st }}$ Assessment } & & \multicolumn{2}{c}{$2^{\text {nd }}$ Assessment } & \\
\cline { 2 - 3 } & Mean & SD & & Median & SD & -value \\
\hline Soccer heading & 27.7 & 18.6 & & 42.3 & 25.0 & 0.1129 \\
Tightrope walk & 19.3 & 6.1 & & 25.7 & 10.4 & 0.0348 \\
Table tilt & 73.3 & 14.5 & & 66.1 & 18.8 & 0.1622 \\
Ski slalom & 34.6 & 8.8 & & 55.3 & 26.2 & 0.0053 \\
\hline
\end{tabular}

SD: standard deviation; $p<0.05$ was considered significant. Significant $p$ values are in bold.

the elastic rigidity typical in injuries of the pyramidal system. It can be unilateral or bilateral, affecting all muscles indiscriminately. Rigidity and tremor are the initial symptoms of the disease in most cases ${ }^{2}$. Imbalance occurs due to the loss of the postural reflexes. Muscle and joint proprioception, the vestibular system and vision are some of the input sources for the extrapyramidal system to control the postural tonus ${ }^{14}$. Meneses and Teive ${ }^{14}$ reported that these signs and symptoms are typical and result from a deficit of dopamine in the substantia nigra. This disease affects the extrapyramidal system, comprising the thalamus, cerebellum and basal ganglia. Dopamine deficiency causes nigrostriatal pathway dysfunctions and subsequent disorder in the basal ganglia circuitry, causing motor disorders due to the hypoactivity of the direct basal ganglia pathway and the hyperactivity of the indirect basal ganglia pathway, resulting in an alteration of the thalamic and cortical pathway. The aging of the sensory systems results in nerve cell loss, beginning in the 60s and progressing beyond the $70 \mathrm{~s}^{15}$.

An efficient way to measure intervention success is through the systematic use of evaluation instruments. In this study, the DHI, BBS, SF-36 and SRT were applied before the intervention ( $1^{\text {st }}$ assessment) and after the intervention ( $2^{\text {nd }}$ assessment).

It is believed that the reduction in the total scoring of the DHI in the second assessment indicated that, through the use of VR, benefits were achieved, reported by patients who felt better - in their self-perception assessment - from the incapacitating effects of dizziness, in spite of its occurrence in $43.7 \%$ of the reported complaints. This result corroborated those of Zeigelboim et al. ${ }^{16}$, who assessed 12 patients with PD featuring peripheral vestibulopathy $(83.3 \%)$ and reporting significant improvement in the total scoring of the DHI.

The BBS, which initially featured a high fall risk, showed an improvement in the fall risk after the exercises. This result conforms with researchers ${ }^{17-19}$, who observed the beneficial effects of cognitive-motor training by means of virtual games in patients with PD, with increased scores in the BBS and Dynamic Gait Index scales. Santos et al..$^{20}$ observed improvement in balance and reduction in the fall risk by applying the BBS post-VR in patients with traumatic brain injury. Zeigelboim et al. ${ }^{21}$ applied the BBS before and after using Wii Fit virtual games (Bird's-Eye, Bull's-Eye, Big Top Juggling and Hula Hoop) in four cases of spinocerebellar ataxia, and showed improvement in the high fall risk scores, which changed into low fall risk scores in three patients, with only one patient remaining a high fall risk.

One of the ways to evaluate individuals' independence and functional capacity is by means of the SF-36 questionnaire. In the current study, higher alterations in the patients' functional capacity and mental health in relation to the other assessed aspects were observed between the pre- and posttraining assessments. It was also observed that there was a significant improvement in the ability and mobility of the lower limbs, shown in the SRT outcome, with a reduction of the performance time for movement, after carrying out the VR exercises. This showed that the games used acted on the muscle strength, as evaluated by the patients' improvement. We did not find any scientific literature on the SF-36 and SRT, so we could compare our findings.

By comparing the virtual games used with the results found in the DHI, BBS and SF-36, we found significant results in the $2^{\text {nd }}$ assessment of the Tightrope Walk and Ski Slalom games, which used general strategies of motor coordination, static and dynamic balance, eye-foot coordination, optical kinetic stimuli, flexion and extension of ankles, knees and hip, and side-to-side and pelvic girdle movements. In light of the outcomes, we can conclude that these two games proved to be the most effective for balance training in this population, showing significant results after the $20^{\text {th }}$ rehabilitative therapy session. This suggests that these games may have a high therapeutic potential, and may be recommended as an alternative for motor training in PD. Silva et al..$^{22}$ reported that virtual environments are designed to be more pleasant than the conventional rehabilitative methods. The introduction of game elements and the immediate feedback on the performance increases motivation, encouraging a higher number of repetitions. In another study, Rojas et al. ${ }^{23}$ used the Ski Slalom virtual game to identify the efficacy of this therapeutic treatment on the postural control in participants without neurological disorders. The authors used the Wii Balance Board for data collection on pressure center displacement, as well as movement analysis. The results showed that the game could improve the range of pressure center displacement, suggesting that further studies should be carried out in patients with disorders in motor control processing. Sánchez-López et al. ${ }^{24}$ used several games from the Wii Fit Plus (Free Run, Soccer Heading, Penguin Slide, Hula Hoop, Island Cycling, Perfect 10, Table Tilt, Free Steps and Balance Bubble) in the balance rehabilitation of the elderly. These games fostered saccadic, optokinetic stimuli, smooth pursuit movements, in addition to fine tuning of the pressure center, and training of responsive ankle and hip strategies through a strength training platform, thus enhancing body balance. The authors reported that the improvement could be explained by the process of brain plasticity where there was habituation of the vestibular system due to the repetitive response to the proposed exercises. Mendes et al. ${ }^{25}$ used virtual games 
from the Xbox Kinect, Microsoft, such as Space Pop, 20,000 Leaks, Reflex Ridge and River Rush, which require movements of several body segments in tasks with different levels of cognitive and motor complexity, in seven patients with $\mathrm{PD}$, and observed performance improvement in all the games performed after 14 sessions. The authors reported that the performance enhancement seen suggests that the motor and cognitive skills demanded by the games, impaired in patients with PD, may have increased the potential of their training with the visual and auditory tracks.

Other authors ${ }^{26,27}$ used a protocol with balance exercises from the Wii Fit and observed balance improvement, which suggested that this could be an important technological tool, with the advantage of stability and convenience, and a good cost-benefit relationship, enabling training without a fall risk.

Virtual reality uses stimuli that simulate real life situations, fostering and accelerating the natural mechanisms of neuroplasticity in the CNS by means of specific eye, head and body exercises, correcting or supplying altered or absent sensory information ${ }^{7}$. For each stimulus, a new interaction is needed for every new learning task, and new nerve circuits are activated and new synapses formed. Nerve tissue injury makes healthy nerve cells take over the function of the faulty ones, as far as possible ${ }^{28}$.

We observed in the current study that VR improved balance, generating positive effects on the patients' selfconfidence, influencing their quality of life. These results corroborate several studies already reported. Virtual reality technology is an extremely important additional resource to add to the existing conventional ones. Several possibilities for applying this technology are indicated for a diversified number of neurological diseases and physical disabilities.

In this study, attempting to overcome the limitations of conventional interventions, the technology used in VR proved to be an important neurological rehabilitative tool. This technology may overcome physical disabilities in many cases; especially through its motivational factor when patients perceive their constraints and motor gains.

According to the patients' daily reports, improvements in their proprioception and perception of their spatial body position were observed. As their body adapted to the visual stimuli, movements became better coordinated and, consequently, improvement in balance was observed.

The repetitive practice of motor and cognitive skills impaired in PD was added to the training in the current study, and showed the therapeutic advantages of VR. Repetition facilitates the production of movements by means of neurophysiological and behavioral changes arising from neuroplastic mechanisms, which are extremely important for motor skills relearning.

In conclusion, rehabilitation of the body balance by means of VR proved efficient in improving body balance and functional capacity, reducing fall risk, increasing self-confidence and enhancing the quality of life of patients suffering from PD.

The Tightrope Walk and Ski Slalom virtual games were shown to be the most effective for this population.

\section{References}

1. Westerberg BD, Roberson JB, Stach BA, Silverberg GD, Heit G. The effects of posteroventral pallidotomy on balance function in patients with Parkinson's disease. Stereotact Funct Neurosurg. 2002;79(2):75-87. https://doi.org/10.1159/000070103

2. Teive HA, Bertucci DC, Munhoz RP. Unusual motor and non-motor symptoms and signs in the early stage of Parkinson's disease. Arq Neuropsiquiatr. 2016 Oct;74(10):781-4. https://doi.org/10.1590/0004-282X20160126

3. Teive HA. Etiopatogenia da doença de Parkinson. In: Meneses MS, Teive HA, editors. Doença de Parkinson. Rio de Janeiro: Guanabara Koogan; 2003. pp. 33-7.

4. Schrag A, Schott JM. Epidemiological, clinical, and genetic characteristics of early-onset parkinsonism. Lancet Neurol 2006; 5 (4): 355-363. https://doi.org/10.1016/S1474-4422(06)70411-2

5. Zeigelboim BS, Jurkiewicz AL, Fukuda Y, Mangabeira-Albernaz PL. Alterações vestibulares em doenças degenerativas do sistema nervoso central. Pro Fono. 2001;13(2):263-70.

6. Smiley-Oyen AL, Cheng HY, Latt LD, Redfern MS. Adaptation of vibration-induced postural sway in individuals with Parkinson's disease. Gait Posture. 2002 Oct;16(2):188-97. https://doi.org/10.1016/S0966-6362(02)00005-X

7. Herdman SJ. Vestibular rehabilitation. Curr Opin Neurol. 2013 Feb;26(1):96-101. https://doi.org/10.1097/WCO.0b013e32835c5ec4
8. Manso A, Ganança MM, Caovilla HH. Vestibular rehabilitation with visual stimuli in peripheral vestibular disorders. Braz J Otorhinolaryngol. 2016 Mar-Apr;82(2):232-41.

9. Dores AR, Barbosa F, Marques A, Carvalho IP, De Sousa L, Castro-Caldas A. Realidade virtual na reabilitação: por que sim e por que não? Uma revisão sistemática. Acta Med Port. 2012 Nov-Dec;25(6):414-21.

10. Jacobson GP, Newman CW. The development of the Dizziness Handicap Inventory. Arch Otolaryngol Head Neck Surg. 1990 Apr;116(4):424-7. https://doi.org/10.1001/archotol.1990.01870040046011

11. Berg K, Wood-Dauphinée S, Williams JI, Gayton D. Measuring balance in the elderly: preliminary development of an instrument. Physiother Can. 1989;41 (6):304-11. https://doi.org/10.3138/ptc.41.6.304

12. Ware JE Jr, Sherbourne CD. The MOS 36-item shortform health survey (SF-36). I. Conceptual framework and item selection. Med Care. 1992 Jun;30(6):473-83. https://doi.org/10.1097/00005650-199206000-00002

13. Bastone AC, Jacob Filho W. Effect of an exercise program on functional performance of institutionalized elderly. J Rehabil Res Dev. 2004 Sep;41(5):659-68. https://doi.org/10.1682/JRRD.2003.01.0014

14. Meneses MS, Teive HA. Doença de Parkinson: Aspectos Clínicos e Cirúrgicos. Rio de Janeiro: Guanabara Koogan; 1996. 
15. Whitney SL. Tratamento do idoso com disfunção vestibular. In: Herdman SJ, editor. Reabilitação vestibular. 2a ed. São Paulo: Manole; 2002. p. 505-28.

16. Zeigelboim BS, Klagenberg KF, Teive HA, Munhoz RP, Martins-Bassetto J. Vestibular rehabilitation: clinical benefits to patients with Parkinson's disease. Arq Neuropsiquiatr. 2009 Jun;67(2a):219-23. https://doi.org/10.1590/S0004-282X2009000200009

17. Mhatre PV, Vilares I, Stibb SM, Albert MV, Pickering L, Marciniak CM et al. Wii Fit balance board playing improves balance and gait in Parkinson disease. PM R. 2013 Sep;5(9):769-77. https://doi.org/10.1016/j.pmrj.2013.05.019

18. Pompeu JE, Arduini LA, Botelho AR, Fonseca MB, Pompeu SM, Torriani-Pasin C et al. Feasibility, safety and outcomes of playing Kinect Adventures! ${ }^{\text {TM }}$ for people with Parkinson's disease: a pilot study. Physiotherapy. 2014 Jun;100(2):162-8. https://doi.org/10.1016/j.physio.2013.10.003

19. Pompeu JE, Mendes FA, Silva KG, Lobo AM, Oliveira TP, Zomignani AP et al. Effect of Nintendo Wii ${ }^{\mathrm{TM}}$-based motor and cognitive training on activities of daily living in patients with Parkinson's disease: a randomised clinical trial. Physiotherapy. 2012 Sep;98(3):196-204. https://doi.org/10.1016/j.physio.2012.06.004

20. Santos SM, Nishimoto MG, Pierucci A, Lima RAO. Equilíbrio em pacientes com traumatismos encefálicos que praticam natação e realidade virtual. Rev Neurocienc. 2013;21(1):89-93. https://doi.org/10.4181/RNC.2013.21.751.5p

21. Zeigelboim BS, Souza SD, Mengelberg H, Teive HA, Liberalesso PB. Vestibular rehabilitation with virtual reality in spinocerebellar ataxia. Audiol Commun Res. 2013 Apr-June;18(2):143-7. https://doi.org/10.1590/S2317-64312013000200013
22. Silva DO, Briani RV, Floride CS, Aragão FA. Treinamento de sujeitos hemiparéticos em tarefas virtuais utilizando o Nintendo Wii. Fisioter Bras. 2013;14(45):344-50.

23. Rojas VG, Cancino EE, Silva CV, López MC, Arcos JF. Impacto del entrenamiento del balance a través de realidad virtual en una población de adultos mayores. Int J Morphol. 2010;28(1):303-8. https://doi.org/10.4067/S0717-95022010000100044

24. Sánchez-López CR, Perestelo-Pérez L, Escobar A, López-Bastida J, Serrano-Aguilar P. Calidad de vida relacionada con la salud en pacientes con ataxias espinocerebelosas. Neurologia. 2017 Apr;32(3):143-51. https://doi.org/10.1016/j.nrl.2015.09.002

25. Mendes FA, Arduini L, Botelho A, Cruz MB, Santos-Couto-Paz CC, Pompeu SM et al. Pacientes com Doença de Parkinson são capazes de melhorar seu desempenho em tarefas virtuais do Xbox Kinect@: "uma série de casos. Motricidade. 2015;11(3):68-80. https://doi.org/10.6063/motricidade.3805

26. Loureiro AP, Ribas CG, Zotz TG, Chen R, Ribas F. Feasibility of virtual therapy in rehabilitation of Parkinson's disease patients: pilot study. Fisioter Mov. 2012;25(3):659-66. https://doi.org/10.1590/S0103-51502012000300021

27. Treml CJ, Kalil Filho FA, Ciccarino RF, Wegner RS, Saita CY, Corrêia AG. [The Balance Board plataform used as a physiotherapy resource in elderly]. Rev Bras Geriatr Gerontol. 2013 Oct/Dec;16(4):759-68. Portuguese. https://doi.org/10.1590/S1809-98232013000400010

28. Costa WC, Bôas AV, Silva AM, Reis LM, Kosour C, Silva AT. Análise da realidade virtual em pacientes com vestibulopatia periférica: relato de caso. Rev Neurocienc. 2015;23(2):275-80. https://doi.org/10.4181/RNC.2015.23.02.977.6p 